\title{
Optimization of Electrical Distribution System Maintenance Process Based on Failure Modes
}

\author{
M. Hajivand ${ }^{1,2^{*}}$, M. Zahedi Vahid ${ }^{3}$, F. Goudarzvand Chegini $^{4}$, P. Rahmati-Kahkha ${ }^{5}$ and R. \\ Hajivand ${ }^{2,6}$
}

1. Aerospace Research Institute, Ministry of Science, Research and Technology

2. Young Researchers and Elite Club, Borujerd Branch, Islamic Azad University, Borujerd

3. Department of Electrical and Computer Engineering, University of Sistan and Baluchestan, Zahedan

4. Islamic Azad University of Rasht

5. Department of Electrical Engineering, University of Zabol, Zabol

6. Bakhtar Regional Electric Company, Arak

\begin{abstract}
This paper presents a novel scheme for comprehensive planning of reliability-centered maintenance (RCM) in the electrical distribution system to minimize the costs of cable repair and maintenance. To this end, a new formulation is proposed by taking into account the maintenance costs for different cases, repairs, repair-caused load projects, and energy purchase or generation costs. To solve the given complex problem, one of the most powerful and newest particle intelligence techniques called GSO algorithm is employed. Simulations are carried out on a 30-bus test network. Moreover, three scenarios and ten cases are applied in the process of extracting results to analyze the impact of various items on parameters of the objective function.
\end{abstract}

Keywords: Reliability-Centered Maintenance, Markov Model, Distribution Network, Group Search Optimization.

\section{Introduction}

The operation of most powers is such that not any interruption could overload other components of the system. Reliability in a power system can be divided into three main functions performed at the network control centre: system monitoring, event analysis, and corrective action analysis.

System monitoring provides operators with new and proper information on power system conditions. Event analysis allows systems to operate reasonably [1-2].

Corrective action analysis permits the operation personnel to change the system operation mode in case of an overload or when the event analysis section predicts an acute issue when a particular interruption occurs. One simple example of corrective actions is power displacement from one unit to another. To enhance the efficacy of RCM, Case-Based Reasoning (CBR), as artificial intelligence (AI) technology, successfully introduced into the RCM analysis process, and a framework for Intelligent RCM Analysis (IRCMA) was studied [3]. The IRCMA idea is based on the fact that previously recorded values of RCM analysis on similar items can be referenced and applied to the current RCM analysis on a new item. The importance of obtaining the application of the RCM method, which accurately meets the different needs of the generation process, independent of its technical complexity or difficulty in accessing industrial workshop equipment is presented [4].

The importance of obtaining the application of the RCM method is also mentioned in the literature, which accurately meets the different needs of the generation process, independent of its technical complexity or difficulty in accessing industrial workshop equipment. The way systems thinking approach can be used for identifying relevant aspects and possible interactions between the RCM approach and wind turbine gearboxes and bridging the gaps in the system to add value to the trade section have also been discussed [5].

The present study proposes to apply systematic approaches to wind turbine gearbox and maintenance, helping to optimize the value of equipment at the

1. Corresponding Author Email: mohamadhajivand@gmail.com 
lowest total cost to the system operator. Two main discussions of the RCM include ensuring safety through preventive maintenance and when safety is discarded, and preserving the best and cost-effective applicability [6]. For distribution system equipment, operations must be considered at the same level of safety. The RCM model has been used for developing a maintenance strategy in the transmission system [7]. This model is applicable to transmission components whose destruction can be classified according to the severity of aging. Particle Swarm Optimization (PSO) is used to derive the optimal RCM strategy from a high class of possible maintenance scenarios. Novoa [8] examines the stochastic programming model to minimize the lifespan cost of distributed generation systems (DGs) under the criterion of energy reliability, i.e. the loss of load probability. In practice, our focus is on the DG system realized by renewable wind turbine technology.

A new approach was introduced as the first step in implementing the RCM in combined power generation and transmission systems to determine the components essential for the desired maintenance management [9]. The criticality assessment focuses on the probability of occurrence of component failure and cost-based consequences. A financial method has also been introduced to evaluate the RCM [10]. Moreover, the same reference suggests that by considering RCM as an investment decision rather than a test, the economic feasibility in a potential application can be identified before essential resources are provided. Maintenance planning of power circuit breakers (CBs) based on the concept of RCM was presented in [11], where the proposed approach is used on a $400 \mathrm{kV}$ grid in Khorasan province, Iran. The RCM approach considers the technical condition and importance of each circuit breaker from a network point of view. RCM is a systematic approach that maintains the balance between preventive and corrective maintenance actions.

The main objective of this study is to present a realistic technique for designing a comprehensive plan regarding the maintenance of electrical distribution systems to minimize equipment maintenance costs. The objective function of the problem includes maintenance costs for various modes, repairs, load project due to repair, and cost of energy purchase or production. To solve this complex problem, one of the most powerful and newest techniques of particle intelligence, namely the Groups Search Optimization (GSO) algorithm, is employed. Simulations were performed on a 30-bus system, and three scenarios and ten cases were applied to the process of extracting results to investigate the effects of different items on the objective function parameters.

The paper is organized as follows. Section 2 addresses the concept of reliability in distribution systems. The proposed model is introduced in Section
$3 \& 4$. The GSO optimization algorithm is briefly introduced in Section. Finally, Sections 6 and 7 present the simulation results and conclusions, respectively.

\section{Reliability in Distribution Systems}

Some reliability parameters are needed to define the requirements of reliability concept. One of prevalent parameters is Mean Time Between Failures (MTBF), which can be replaced with the failure rate or the frequency of failures in a given period. If MTBF is increased, it means that the reliability of the system will increase. The MFBF parameter is often defined in hours, but sometimes it can be described in a cycle, travelled kilometres, etc.

As previously said, one of the definitions of reliability can be defined as the probability of mission success. From this point of view, one of the special cases is disposable systems or devices that are assigned to perform a specific mission at a given time and under specified conditions. These systems, after being built, remain stationary until the start of their mission and, at a specific time, begin their activity.

Component reliability is one of the most important aspects of evaluating the reliability of a distribution system. Without proper data, the solutions obtained by computer programs will be highly complex, difficult, and unreasonable. It is also cumbersome to obtain accurate information. The reliability data of critical components obtained from or verified by power distribution companies, manufacturers' tests, advanced organizations such as IEEE and CIGRE as well as reputable publications and journals are provided [12]. These quantities are set for the U.S. distribution systems and may not be valid for all systems.

Table 1 is associated with an overhead distribution system with a radial structure in the voltage range of $5 \mathrm{kV}$ to $35 \mathrm{kV}$. Since the equipment is exposed to the weather and other effective parameters, the overhead system will result in a higher failure rate compared with an underground system. Instead, it will be less time consuming to repair them because fixing and repairing air systems is less frequent than underground systems [13]

Table 2 is related to underground systems. Although most of the distribution systems are of overhead type, underground systems are also utilized. 
Table 1. Reliability data for components of overhead distribution systems [13].

\begin{tabular}{|c|c|c|c|c|c|c|}
\hline $\begin{array}{c}\text { Component } \\
\text { (overhead) }\end{array}$ & \multicolumn{3}{|c|}{$\begin{array}{c}\text { Failure Rate } \\
\text { Analytical solution } \\
\text { Monte Carlo } \\
\text { Simulation }\end{array}$} & \multicolumn{3}{c|}{$\begin{array}{c}\text { Repair duration } \\
\text { (overhead) }\end{array}$} \\
\hline Main circuit & Low & Normal & High & Low & Normal & High \\
\hline $\begin{array}{c}\text { Overhead } \\
\text { transformer }\end{array}$ & 0.02 & 0.1 & 0.3 & 2 & 4 & 8 \\
\hline Sectionalizer & 0.02 & 0.016 & 0.3 & 2 & 4 & 8 \\
\hline Cut-out fuse & 0.004 & 0.014 & 0.14 & 1.5 & 4 & 10 \\
\hline $\begin{array}{c}\text { Line } \\
\text { reconnector }\end{array}$ & 0.004 & 0.009 & 0.03 & 0.5 & 2 & 4 \\
\hline $\begin{array}{c}\text { Voltage } \\
\text { regulator }\end{array}$ & 0.005 & 0.015 & 0.03 & 3 & 4 & 10 \\
\hline
\end{tabular}

Table 2. Reliability data for components of underground distribution systems [13].

\begin{tabular}{|c|c|c|c|c|c|c|}
\hline $\begin{array}{c}\text { Undergroun } \\
\boldsymbol{d} \text { cable }\end{array}$ & \multicolumn{3}{|c|}{$\begin{array}{c}\text { Failure rate } \boldsymbol{\lambda} \\
\text { (mile/year) }\end{array}$} & \multicolumn{3}{c|}{$\begin{array}{c}\text { Repair duration } \boldsymbol{r} \\
\text { (hours) }\end{array}$} \\
\hline Primary cable & Low & $\begin{array}{c}\text { Norma } \\
\text { l }\end{array}$ & High & $\begin{array}{c}\text { Lo } \\
\mathrm{w}\end{array}$ & $\begin{array}{c}\text { Norma } \\
1\end{array}$ & $\begin{array}{c}\text { Hig } \\
\mathrm{h}\end{array}$ \\
\hline $\begin{array}{c}\text { Secondary } \\
\text { cable }\end{array}$ & 0.003 & 0.007 & $\begin{array}{c}0 . \\
587\end{array}$ & 1.5 & 10 & 30 \\
\hline Knee joints & 0.005 & 0.1 & 0.15 & 1.5 & 10 & 30 \\
\hline Transformer & $\begin{array}{c}0.0000 \\
6\end{array}$ & 0.0006 & $\begin{array}{c}0.00 \\
1\end{array}$ & 1 & 4.5 & 8 \\
\hline Switches & 0.001 & 0.01 & 0.05 & 4 & 6.5 & 7.8 \\
\hline
\end{tabular}

\section{RCM Model}

Most of the existing distributed system components have been installed decades ago and have been degraded over time. As a result, the performance of these components has reduced leading to an increased failure rate of components in transmission systems. However, we can prevent further degradation of facilities.

Common Markov model, which is based on fixed failure rates, is appropriate for simulating the consequences of components degradation. The operation status of transmission components is categorized based on the severity of degradation. It has been proved that components status model using the Markov chain [14] is desirable for degraded components. This model is used in the present study to determine to change probabilistic status. Components status model is shown in Fig. 1.

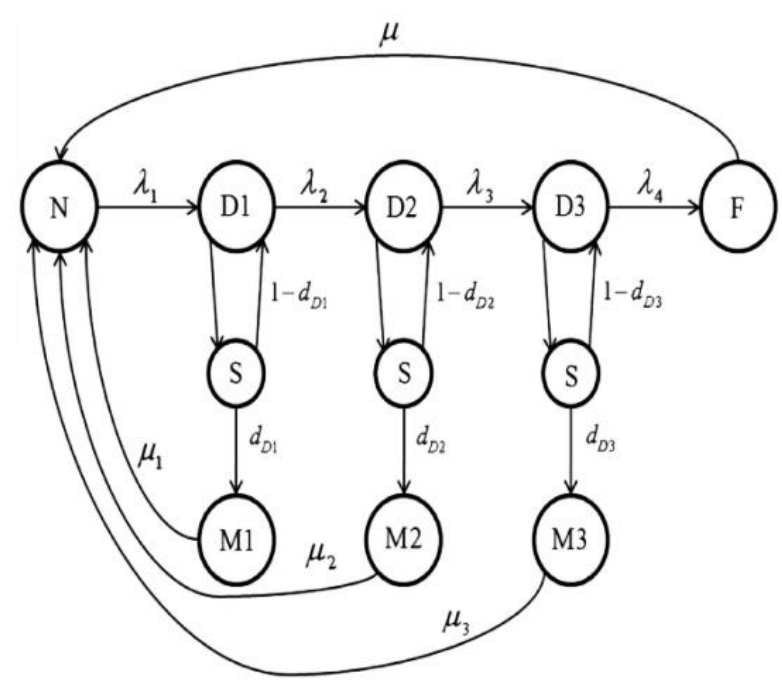

Fig. 1. State component model using Markov chains [14]

The operation status of components is categorized into sub-states by increasing the degradation and destruction level (as normal status $\mathrm{N}$, and destruction status D1 to D3). Status N describes a new system without destruction. A status transfer is controlled by change rates of $\mathrm{k} 1, \mathrm{k} 2, \mathrm{k} 3$, and $\mathrm{k} 4$ described as the inverse of average time consumed for degradation status. Repairing turns a failure status $\mathrm{F}$ into a normal status $\mathrm{N}$ at the repair rate 1 (which is equal to the inverse of average value of repair duration). M1, M2, and M3 represent weak maintenance (depends on D1), strong maintenance (depends on D2), and stronger maintenance (depends on D3). The information related to the status of components (D1, D2, and D3) is extracted from the sensor in real-time (S) and is delivered to the inspector. If maintenance or repair method is carried out, the status of components at a rate of $11,12,13$, or 1 turns into $\mathrm{N}$. This component status model can be adjusted by changing the number of destruction states. The number of destruction states is determined by real degradation level of components and repair and maintenance methods.

Since the assumed distribution system has a ring configuration, analyzing the impact of faulty components on the transmission system can be very difficult and complex. Failure of components affects the neighbouring bus and topology of the whole system as well, leading to changes in power flow. Additionally, the failure of several components can cause blackout of the whole system or increase the generation cost. The current paper presents a model describing the effects of failure, destruction, and maintenance of components on transmission systems based on the overall expected costs (CT) that include costs of generation, power interruption, repair, and maintenance cost [6]. 


\section{Problem Formulation}

Basically, a device can have one of the following five modes:

- Normal, no need for repair,

- Under repair, where the system is disconnected. However, it might that a part of the system is deenergized.

- Weak maintenance, without disconnecting from the system,

- Strong maintenance, without disconnecting from the system,

- Very strong maintenance without disconnecting from the system.

Three last modes are called degraded status. According to the intentions, the objective function of the problem can be formulated as:

$$
F=\sum_{i=1}^{N_{C}}\left(\begin{array}{l}
P_{1} C_{m_{1}} x_{i, 1} L_{i}+P_{2} C_{m_{2}} x_{i, 2} L_{2}+P_{3} C_{m_{3}} x_{i, 3} L_{3} \\
+P_{r} C_{r} x_{i, r} T_{f f} L_{r}+P_{r} C_{o} P_{o, i} x_{o, i} T_{f f} L_{r}+ \\
765 \times\left(1-P_{1}-P_{2}-P_{3}-P_{r}\right)\left(C_{S E}-C_{B E}\right) P_{i n} x_{i n}
\end{array}\right)
$$

where,

\begin{tabular}{|c|c|}
\hline$P_{1}, P_{2}, P_{3}:$ & Occurrence probabilities of modes 1,2 , and 3 , \\
\hline$C, C_{m 2}, C_{m 3}:$ & $\begin{array}{l}\text { Maintenance cost of the cable in modes } 1,2 \text {, } \\
\text { and } 3 \text {, }\end{array}$ \\
\hline$L_{i}:$ & Cable length of section $\mathrm{i}^{\text {th }}$ \\
\hline$x_{i, 1,2,3}:$ & $\begin{array}{l}\text { A binary variable showing the occurrence or } \\
\text { not-occurrence of modes } 1,2 \text {, and } 3 \text { for cable } \\
\text { section, }\end{array}$ \\
\hline$P_{r}:$ & Occurrence probability of repairs, \\
\hline$C_{r}:$ & Repairs cost, \\
\hline$x_{r, i}:$ & $\begin{array}{l}\text { A binary variable showing the occurrence or } \\
\text { not-occurrence of repairs for cable section } i^{\text {th }} \text {, }\end{array}$ \\
\hline$T_{\text {off: }}$ & Repairs time, \\
\hline$C_{o}:$ & Imposed cost by cable section $i^{\text {th }}$ \\
\hline$P_{o, i}:$ & $\begin{array}{l}\text { The amount of load disconnected due to the } \\
\text { changes in the cable section } i^{\text {th }} \text {, }\end{array}$ \\
\hline$x_{o, i}:$ & $\begin{array}{l}\text { A binary variable representing the occurrence } \\
\text { or not-occurrence of disconnection of cable } \\
\text { section } i^{t h} \text {, }\end{array}$ \\
\hline$P_{i n}:$ & $\begin{array}{l}\text { The amount of load remaining in the circuit due } \\
\text { to the occurrence of changes in cable section } \\
i^{\text {th }} \text {, }\end{array}$ \\
\hline$x_{i n:}$ & $\begin{array}{l}\text { A binary variable denoting the occurrence and } \\
\text { not-occurrence of disconnection of the faulty } \\
\text { cable section }\end{array}$ \\
\hline
\end{tabular}

\section{Groups Search Optimization (GSO) Algorithm [15-16]}

Individual available in the GSO are basically categorized into three groups: a) Generator: There is only one generator at each iteration. This vector scans three points around it for finding a better status.

b) Seeker: Other individuals of the population (excluding the generator) are seekers.

c) Scattered: These individuals also move randomly.

The population of the GSO algorithm is called a group, and each individual of the population is named member. In an n-dimension search space, the $i$-th member at the $k$-th search iteration has status $X \neg i k \in R n$ and a vertex angle $\Phi i k=(\Phi i 1 k, \ldots, \Phi k i(n-1)) \in R n-1$. The search trajectory of the $i$-th member, which is a unit vector $\operatorname{Dik}(\Phi i k)=(d i 1 k, \ldots, d k i(n-1)) \in R n$, can be calculated through a polar for a transformation into coordinated Cartesian.

$$
\begin{aligned}
& d_{i_{1}}^{k}=\prod_{q=1} \cos \left(\phi_{i_{q}}^{k}\right) \\
& d_{i_{1}}^{k}=\sin \left(\phi_{i_{(j-1)}^{k}}^{k}\right) \cdot \prod_{q=1} \cos \left(\phi_{i_{q}}^{k}\right) \quad(j=2, \ldots, n-1)
\end{aligned}
$$

$$
d_{i_{1}}^{k}=\sin \left(\phi_{i_{(j-1)}}^{k}\right)
$$

Initially, the iteration value is set zero $(k=0)$, and the initial random matrix $X_{i}$ and vertex angle $(\varphi i)$ of all members are initialized. The fitness values of initial members $\left(f\left(X_{i}\right)\right)$ are calculated. The procedure continues until the termination criteria are satisfied. For each member $i$ in the group, the following seven operations are performed:

\begin{tabular}{|l|l|}
\hline Generator selection: & Finding generator $X_{p}$ of the group \\
\hline Generation run: & $\begin{array}{l}\text { The generator scans at zero } \\
\text { angles and then scans and } \\
\text { samples three points in its } \\
\text { neighborhood. }\end{array}$ \\
\hline $\begin{array}{l}\text { Finding the best } \\
\text { solution with the best } \\
\text { source (fitness } \\
\text { value): }\end{array}$ & $\begin{array}{l}\text { If the best point includes a better } \\
\text { source than the available status, it } \\
\text { moves towards that; otherwise, it } \\
\text { stays at its current status and } \\
\text { determines its path. }\end{array}$ \\
\hline Search: & $\begin{array}{l}\text { Random selection of 80\% of the } \\
\text { remaining members to perform } \\
\text { the search action. }\end{array}$ \\
\hline Scattering: & $\begin{array}{l}\text { The remaining members scatter } \\
\text { to perform sorting action. }\end{array}$ \\
\hline $\begin{array}{l}\text { Producing an angle } \\
\text { for a random } \\
\text { movement: }\end{array}$ & Using Eqs. (2), (3) \& (4). \\
\hline $\begin{array}{l}\text { Selecting a random } \\
\text { distance lI: }\end{array}$ & $\begin{array}{l}\text { Using the movement towards a } \\
\text { new point. }\end{array}$ \\
\hline Fitness calculation: & $\begin{array}{l}\text { Calculating the fitness value of } \\
\text { the available member, } f\left(X_{i}\right) .\end{array}$ \\
\hline
\end{tabular}


The above seven steps are iterated for all particles. The termination criterion of the optimization process (the number of iterations) is evaluated. In case the criterion is met, the algorithm stops. Fig. 2 shows the flowchart of optimization using the GSO algorithm.

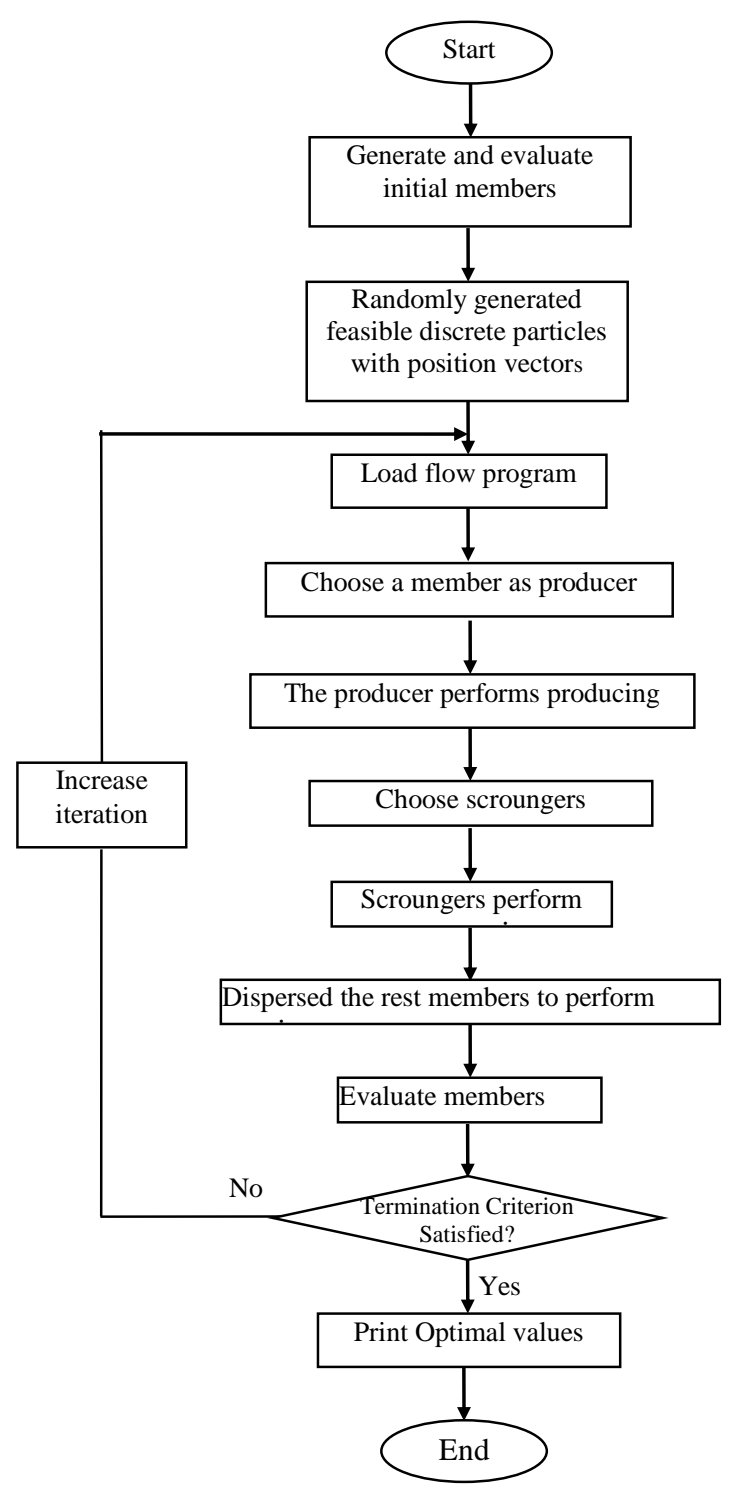

Fig. 2. Flowchart of optimization using the GSO algorithm.

\section{Simulation Results}

After that the concepts and formulation of the problems are presented; tests on the sample network are carried out using MATLAB $^{\circledR} 2016$ on the IEEE 30-bus standard network. Fig. 3 shows single-line diagram of the sample network. For the given network, three repair cases $(P 1, P 2$, and $P 3)$ in $\mathrm{m} /$ year and corresponding to them, three costs $(C 1, C 2$, and $C 3)$ in $\$$ are defined. In case of not resolving the problems in these cases, the device will need disconnecting from the network and fundamental repairs with a rate of $\mathrm{Pr}$ and cost of $\mathrm{Cr}$. The values of this parameter for a 48-hour repair period are listed in Tables 3 \& 4.

Table 3. Failure rate values for different cases [13]

\begin{tabular}{|c|c|c|c|c|}
\hline Rate & P1 & P2 & P3 & Pr \\
\hline Value & 0.15 & $\begin{array}{c}0.1 \\
2\end{array}$ & 0.1 & 0.8 \\
\hline
\end{tabular}

Table 4. Corresponding costs of failure rates for different cases [13]

\begin{tabular}{|c|c|c|c|c|}
\hline Rate & C1 & C2 & C3 & Cr \\
\hline $\begin{array}{c}\text { Valu } \\
\text { e }\end{array}$ & 400 & 600 & 800 & 90 \\
\hline
\end{tabular}

Three different scenarios are defined for the abovementioned network:

- Scenario 1: Change of repair costs

The main objective in this scenario is to multiply the triple maintenance steps $(C 1, C 2$, and $C 3)$ to examine the impact of maintenance cost on the number of maintenance implementation steps and to achieve major repairs.

- Scenario 2: Changes in maintenance rate This scenario studies the effect of the numerical value of maintenance on reaching the major repair $(P r)$ time.

- Scenario 3: Change of repair duration By changing the repair duration $(T r)$, its impact on the under-study parameters will be investigated.

In the process of extracting results, maintenance cost parameters for modes 1,2 and $3(H 1, H 2$ and $H 3)$, repair cost $(\mathrm{Hr})$, repair-caused load project cost $(\mathrm{Ho})$, purchase or production cost of energy $(\mathrm{Hi})$, and the target function (F) will all be represented in \$. The following five conditions are also defined for protection or maintenance of cables in sections (cables between buses):

- Zero: No maintenance required

- One: Requires partial maintenance

- Two: Requires strong maintenance

- Three: Requires very strong maintenance

- Four: Need repairs

Importantly, all table values must be multiplied by 1000. Also, missing each section in the tables means that that step has not been done.

\section{Scenario 1: Changing maintenance costs}

In this scenario, maintenance costs are increased. For the above scenario, the following three cases can be defined:

- Case 1 (Base): Costs are without coefficients,

- Case 2: The cost of the first stage is multiplied by one thousand,

- Case 3: The cost of the first and second stages is multiplied by one thousand,

- Case 4: The cost of the first, second, and third stages is multiplied by one thousand. 
As noted above, Table 5 gives the values obtained from the application of Scenario 1.

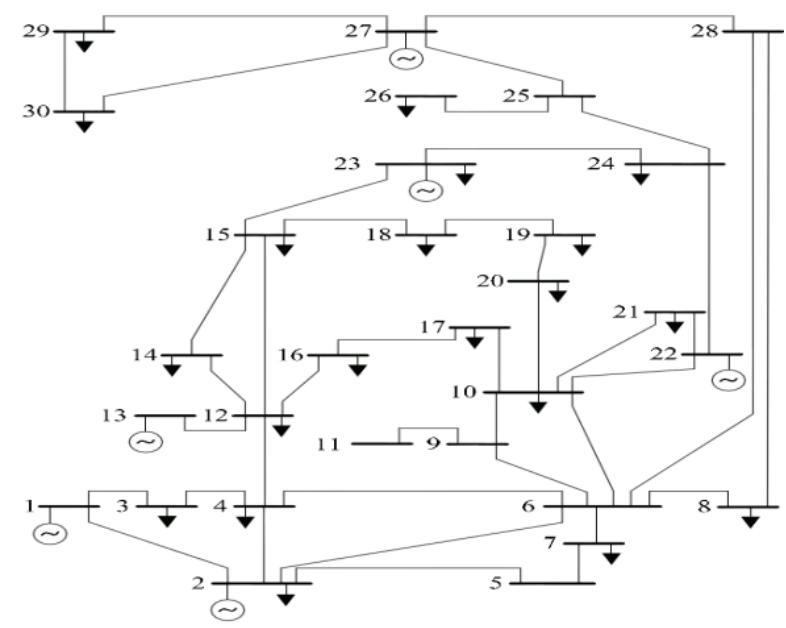

Fig. 3. Single-line diagram of 30-bus test network [13]

Table 5. Parameter values in Scenario 1

\begin{tabular}{|c|c|c|c|c|}
\hline Parameter & Case 1 & Case 2 & Case 3 & Case 4 \\
\hline $\mathrm{H} 1$ & 116 & 174 & 219 & 287 \\
\hline $\mathrm{H} 2$ & 216 & 235 & 280 & 315 \\
\hline $\mathrm{H} 3$ & 99 & 306 & 483 & 512 \\
\hline $\mathrm{Hr}$ & 59 & 154 & 715 & 2803 \\
\hline $\mathrm{Ho}$ & 243 & 419 & 372 & 1989 \\
\hline $\mathrm{Hi}$ & 12710 & 12530 & 12659 & 11213 \\
\hline $\mathrm{F}$ & 13443 & 13644 & 14229 & 16005 \\
\hline
\end{tabular}

According to the values presented in Table 5, it can be said that the total cost has increased with the increase in the maintenance cost, and practically, that stage of maintenance is not performed. The remarkable increase in $\mathrm{Ho}$ and $\mathrm{Hr}$ parameters in the fourth case is interesting. The protection or maintenance status of the cables in sections in Scenario 1 is seen in Fig. 4.

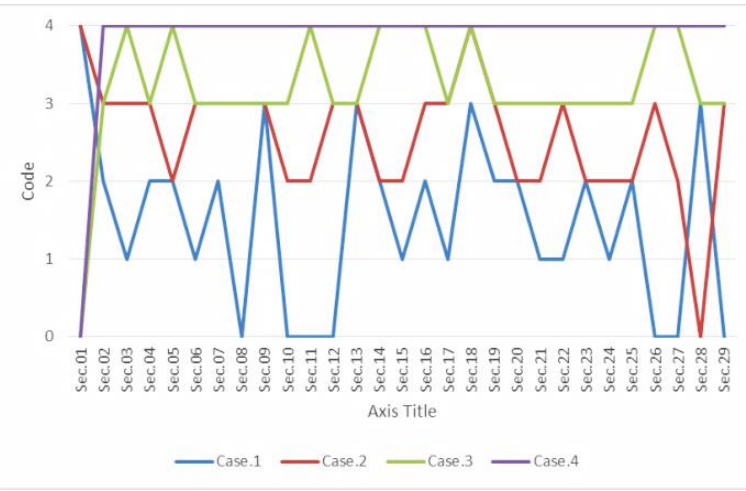

Fig. 4. Protection or maintenance status of the cables in sections in Scenario 1
It can be seen from the results of Fig. 4 that in the fourth case only the first section does not require maintenance, and in the other sections, repairs must be done if no maintenance is required. The greatest changes can be observed in Case 1 (base case) where repair is never needed. In the third case, neither the cable nor the section should be repaired, which will impose the network great cost.

\section{Scenario 2: Changes in maintenance rate}

In the second scenario, we change the triple maintenance rate to investigate the impact of its changes on network costs. For this purpose, an unchanged case (base case) is considered, and in the other two cases, the maintenance rates of $P 1, P 2$, and $P 3$ are reduced by $50 \%$ relative to the corresponding values in Table 1 . Hence, we can write:

- Case 1:50\% reduction in the maintenance rate

- Case 2 (Basic): No changes in the maintenance rate

- Case 3: 50\% increase in the maintenance rate

The values of this scenario are listed in Table 6

Table 6. Parameter values in Scenario 2

\begin{tabular}{|c|c|c|c|}
\hline Parameter & Case 1 & Case 2 & Case 3 \\
\hline $\mathrm{H} 1$ & 75 & 116 & 64 \\
\hline $\mathrm{H} 2$ & 226 & 216 & 83 \\
\hline $\mathrm{H} 3$ & 226 & 99 & 28 \\
\hline $\mathrm{Hr}$ & 207 & 59 & 154 \\
\hline $\mathrm{Ho}$ & 105 & 243 & 418 \\
\hline $\mathrm{Hi}$ & 8665 & 12710 & 16721 \\
\hline $\mathrm{F}$ & 9804 & 13443 & 17468 \\
\hline
\end{tabular}

Based on the results of Table 4, it can be claimed that increasing the maintenance factor directly affects network costs. This increase is almost linear and increases the number of costs by $50 \%$. It should be noted that the maintaining costs of the triple modes are inconsistent with other costs, and increasing the maintenance coefficient results in lower costs. However, on the other hand, it results in the costs of repair and energy generation. Refer to Fig. 5 for the protection or maintenance status of the cables in the second scenario.

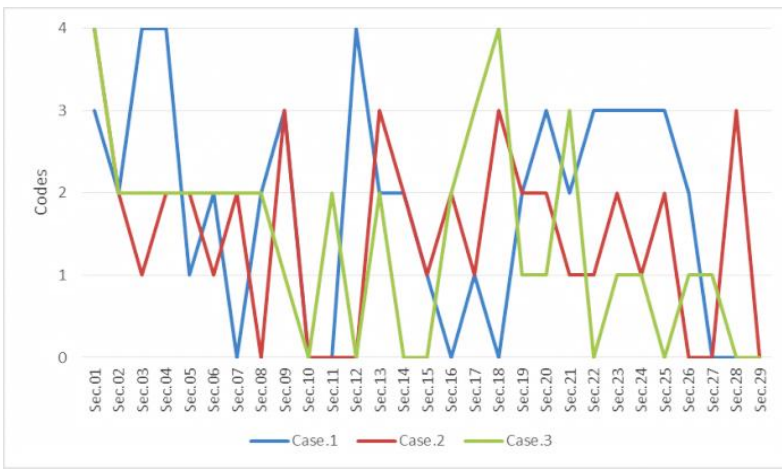

Fig. 5. Protection or maintenance status of cables in sections in Scenario 2 
Given the values are shown in Fig. 5, it can be said that the amplitude of the changes at first case is much greater and there is a greater need for repairs (code 4). The third case also has the lowest maintenance value.

\section{Scenario 3: Changing the repair time}

In the last scenario, the repair time is changed. In the basic mode, this time is 48 hours. In the other two cases, this time is increased and reduced by 24 hours. So for the third scenario, we have:

- Case 1: 24-hour repair time

- Case 2 (Basic): 48-hours repair time

- Case 3: 72-hours repair time

The results of this scenario are listed in Table 7.

Table 7. Parameter values in Scenario 3

\begin{tabular}{|c|c|c|c|}
\hline Parameter & Case 1 & Case 2 & Case 3 \\
\hline $\mathrm{H} 1$ & 101 & 116 & 152 \\
\hline $\mathrm{H} 2$ & 87 & 216 & 143 \\
\hline $\mathrm{H} 3$ & 111 & 99 & 204 \\
\hline $\mathrm{Hr}$ & 238 & 59 & 314 \\
\hline $\mathrm{Ho}$ & 506 & 243 & 411 \\
\hline $\mathrm{Hi}$ & 12016 & 12710 & 13165 \\
\hline $\mathrm{F}$ & 13059 & 13443 & 13664 \\
\hline
\end{tabular}

According to Table 7 , it can be argued that increasing the repair time, in addition to its total increase, virtually precludes selecting $\mathrm{Hr}$ and $\mathrm{Ho}$ parameters. This increase is further reflected in the increase in the parameter Hi. It is interesting to see the reduction in the $H 2$ parameter value. The protection or maintenance status of the cables in the third scenario is illustrated in Fig. 6.

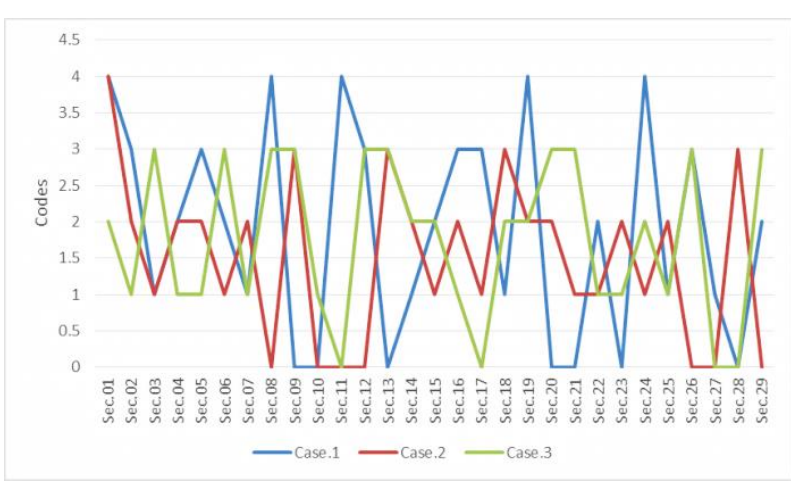

Fig. 6. Protection or maintenance status of the cables in Scenario 3

Regarding the results given in Fig. 6, one can claim that the highest number of repairs is observed in the first case (reduced repair time). In the third case, however, the number of sections that their cables need maintenance is higher.

\section{Conclusions}

In this paper, comprehensive planning of reliabilitycentered maintenance (RCM) has been implemented using the GSO algorithm with the objective of minimizing the costs of repair and maintenance of cables in a 30-bus distribution network. In the modeling and formulation processes of the problem, it has been tried to scientifically include all related parameters within the objective function. To this end, the maintenance cost for cases 1,2 , and $3(H 1, H 2$, and $H 3)$, repair cost $(H r)$, repair-caused load project cost $(\mathrm{Ho})$, energy purchase or generation cost $(\mathrm{Hi})$, all in $\$$ are included in the objective function $(F)$. Three scenarios and ten cases are applied in the process of extracting results to analyze the impact of various items on parameters of the objective function. Furthermore, Conditions of cables are also determined by the level of repair and maintenance required.

Obtained results from simulations show that most of network costs are due to energy purchase or generation (Hi). From Scenario 1 one can conceive that without maintenance the $\mathrm{Ho}$ cost is increased, and practically cables have to be repaired or even replaced. If the maintenance cost is reasonable and performing the maintenance operation is planned, almost no changes are required in the useful lifespan of the cable, and the operating cost is reduced. While increasing the maintenance coefficient reduces the maintenance cost, the overall network cost is increased as well. By decreasing the repair duration, the number of cables that need to be repaired is increased. However, by increasing the repair duration, the number of cases that do not need maintenance is increased. Increase in the value of parameter $H 1$ is mostly due to the increase in the number of repair hours. An increase in parameters $H 2$ and $H 3$ is mostly due to the increase in maintenance costs. Parameter $\mathrm{Hr}$ presents the least changes in the scenarios and the applied cases. The change of maintenance rate for other changes causes the greatest impact on this parameter. The behavior patterns of parameters $\mathrm{Ho}$ and $\mathrm{Hi}$ are analogous and identical. The change in overall maintenance cost has the greatest effect on these parameters. The minimum and maximum amounts of the overall cost are given in the first and third cases of the second scenario.

\section{References}

[1] Roy Billinton, Ronald N. Allan, "Reliability Evaluation of Power Systems," Spring Street, New York, 1996.

[2] M. Nadjafi, M. Hajivand, " Improving Reliability and Reducing Power Loss in Power Distribution Network by Determining Optimal Location and Size of Capacitor Banks," International Journal of Reliability, Risk and Safety: Theory and Application, 1, (2018), 25-33.

[3] Zhonghua Cheng, Xisheng Jia, Ping Gao, Su Wu, Jianzhao Wang, "A framework for intelligent reliability centered maintenance analysis," Reliability Engineering and System Safety, 93, (2008), 784-792. 
[4] J.A. Sainz, M.A. Sebastián, "Methodology for the Maintenance Centered on the Reliability on facilities of low accessibility, " Procedia Engineering 63 (2013) 852 860.

[5] Joel Igba, Kazem Alemzadeh, Ike Anyanwu-Ebo, Paul Gibbons, John Friis, "A Systems Approach towards Reliability-Centred Maintenance (RCM) of Wind Turbines," Procedia Computer Science 16 (2013) 814 823.

[6] B. Yssaad, M. Khiat, A. Chaker, "Reliability centered maintenance optimization for power distribution systems, "Electrical Power and Energy Systems 55 (2014) 108-115.

[7] J.H. Heo, M.K. Kim, J.K. Lyu, "Implementation of Reliability-Centered Maintenance for transmission components using Particle Swarm Optimization," Electrical Power and Energy Systems 55 (2014) 238-245.

[8] Clara Novoa, Tongdan Jin, "Reliability centered planning for distributed generation considering wind power volatility," Electric Power Systems Research 81 (2011) 1654-1661.

[9] Rahim Ghorani, Mahmud Fotuhi-Firuzabad, Payman Dehghanian, Wenyuan Li, "Identifying critical components for reliability centred maintenance management of deregulated power systems, " IET Gener. Transm. Distrib., 2015, Vol. 9, Iss. 9, pp. 828-837.

[10] D.J. Bowler, P.L. Primrose, R. Leonard, "Economic evaluation of reliability-centred maintenance (RCM):an electricity transmission industry perspective," IEE Proc.4mer. T mran Dnib, Vol. 142, No. I, January I995, pp. 9-17.

[11] Morteza Abbasghorbani, Habib Rajabi Mashhadi, Yaser Damchi, "Reliability-centred maintenance for circuit breakers in transmission networks, " IET Gener. Transm. Distrib., 2014, Vol. 8, Iss. 9, pp. 1583-1590.

[12] Maryam Falah nezhadnaeini; Mohammad Hajivand; Reihaneh Karimi; Mohammad Karimi, "Optimal Recloser Placement by Binary Differential Evolutionary Algorithm to Improve Reliability of Distribution System," JOURNAL Islamic Azad University E-Branch, Vol. 3, Iss. 2, 2014, pp. 1583-1590.

[13] Tehran Electricity Distribution company, https://www.tbtb.ir/

[14] Rabiner, L. R. (1989). "A tutorial on hidden Markov models and selected applications in speech recognition." Proceedings of the IEEE 77(2): 257-286.

[15] Yan X., Yang W., Shi H., "A group search optimization based on improved small world and its application on neural network training in ammonia synthesis," Neurocomputing, Vol.97 (2012), pp.94-107.

[16] He S., Wu Q. H., Saunders J. R., "Group Search Optimizer: An Optimization Algorithm Inspired by Animal Searching Behavior, "IEEE Transactions on Evolutionary Computation, Vol.13, No. 5(2009), pp. 973-990. 